\section{The effects of competition and attack}

\section{on physical aggression* $*$}

\author{
JACQUELYN GAEBELEIN and STUART P. TAYLOR \\ Kent State University, Kent, Ohio 44240
}

The effects of competition on the expression of aggression, defined as the delivery of electric shock in a two-person reaction time situation, were examined in two studies. In the first study, the effects of high and moderate competition were examined while a S's opponent was being nonprovocative. In the second study, a no-competition group was included and the opponent's provocation increased across trials. The results of neither study revealed any competition effects on S's shock settings, while the reaction time data from both studies indicated that the $S s$ in the various competition conditions were differentially motivated to respond. The increasing attack of the opponent was found to significantly increase a S's aggressiveness.

In the analysis of the determinants of aggression, several variables have been extensively studied: frustration (Taylor \& Pisano, 1971), aggressive cues (Berkowitz \& LePage, 1967), social pressure (Milgram, 1965), and instrumental value (Buss, 1966). One factor, competition, often considered a potent antecedent of aggression, has received much less attention.

Theorists concerned with the dynamics of international conflict often utilize a competition-aggression hypothesis. Lorenz (1963), Storr (1968), and Rapaport (1960) have argued that as long as there are sovereign states, competition between them will occur and result in wars. The assumption that aggression is inherent in competition has also been made in the discussion of organizational conflict and conflict between individuals. Caplow (1964) has stated, "In virtually all competitive situations some degree of hostility develops between the competitors... [p. 318]." Thibaut \& Kelley (1961) proposed that one learns early the association between attitudes of rivalry and competitive situations: "Such attitudes appear in the form of personal intentions that go beyond merely doing well in competition and involve the goal of hurting the other person, perhaps going out of one's way to do so [p. 228]." According to Berkowitz (1962), the experiencing of a loss in a competitive situation can result in aggression: "The contest may have been a fair one, and the loser may know he is supposed to be a good sport, but he is still thwarted.... Aggressive tendencies are frequently the result [p. 178]." Epstein \& Taylor

*The research was conducted by the first author in partial fulfillment of the MA degree at Kent State University, under the direction of the second author.

tThis research was supported, in part, by a Research Fellowship award ( $\mathrm{MH}$ 44150) from the National Institute of Mental Health, USPHS, to J. Gaebelein.
(1967) reasoned that their competitive situation was particularly suited for the study of aggression in the laboratory because "competition is an integral part of the aggression [p. 267]." Lorenz (1963) has cited numerous examples of aggression in subhuman organisms resulting from competition for territory or sexual privileges and, in discussing sports as a substitute for war, stated "... sport indubitably contains aggressive motivation [p. 217]."

In spite of much hypothesizing and anecdotal evidence, there is a paucity of empirical evidence concerning the assumed competition-aggression relationship.

Those studies which have purported to demonstrate the validity of the competition-aggression hypothesis were not designed as direct tests of the hypothesis; rather, aggressiveness was one result of the competitive manipulations. For instance, Deutsch (1949) found that members of a competitive group displayed less friendliness and helpfulness and more aggressiveness, in terms of verbal comments, toward each other than did members of a cooperative group. Similarly, Sherif \& Sherif (1956), in their study of boys at summer camp, showed that rivalry, induced by means of competitive games, contained elements of aggressiveness including fighting.

The purpose of the present studies was to assess the effects of competition on the expression of direct aggression in a two-person competitive situation developed by Taylor (1967). Competition was defined as Berkowitz, and others, have defined the term: "(1) two or more units, either individuals or groups, engaged in pursuing the same rewards, with (2) these rewards so defined that if they are attained by one unit, there are fewer rewards for the other units in the situation [Berkowitz, 1962, p. 178]., In these studies, Ss competed in a reaction time ( $R T$ ) task in which the person with the faster RT on a trial delivered a shock of an intensity of his choosing to his opponent, while not receiving the shock his opponent had intended for him. On each trial, in accord with the definition of competition, two persons vied for a goal, shock avoidance, which was attainable by only one person at a time.

\section{STUDY 1}

The specific purpose of the first study was to assess the role of competition in the expression of aggression under nonprovocative conditions when $S$ was not attacked or threatened by his opponent. Theoretically, the motivation to aggress should arise from only the competitive element of the situation. Subjects

The Ss were 20 male undergraduates enrolled in the introductory psychology classes at Kent State University. Participation was in partial fulfillment of the course requirements. Procedure

The apparatus and task used are described in detail elsewhere (Taylor, 1967). Briefly, the $S$ was seated at the task board, and a shock electrode was attached to his left wrist. Following determination of the S's "unpleasantness" threshold for shock, he heard a tape recording of the task instructions. Each $S$ was told that he was competing in a RT task with another $S$, who was in an adjoining room. At the beginning of each trial, the $S$ was instructed to select one of five_intensities of shock he wished his opponent to receive, should he have the faster RT on that trial. This was done by pressing one of five buttons. He was then told that at the end of each trial his opponent would receive a shock if S had the faster RT, but if S's RT was slower, he would receive a shock of the intensity chosen by his opponent. Thus, he realized that either he or his opponent would receive a shock, depending upon the outcome of the trial, and that each would determine the intensity of shock received by the other. Actually, there was no opponent. The amount of shock received and sequence of wins and losses were programmed by the $\mathrm{E}$.

All Ss received 25 trials. These consisted of 12 trials under moderate competition instructions and 12 trials under high competition instructions. The extra trial was used to measure S's aggressive reaction to the 24 th trial. All Ss won $50 \%$ of the trials within each of the two conditions.

High competition (HC) was induced by telling $S$ that when he won a particular trial not only would he avoid shock, but he would also receive 
10 cents. In the moderate competition (MC) condition, S competed only in order to avoid shock; money was not involved. The order of the $12 \mathrm{HC}$ trials and $12 \mathrm{MC}$ trials was counterbalanced such that half of the Ss first received the $\mathrm{HC}$ instructions and, at the beginning of the 13th trial, were informed that they would no longer receive money. The other $\mathrm{Ss}$ were informed at the beginning of the 13 th trial that they would win money during the remainder of the experiment.

The attack variable, defined in terms of the opponent's shock settings, was held constant. Minimal attack was induced by programming the opponent to set the No. 1 shock on every trial.

Each trial consisted of four signals: (1) a signal to set the intensity of shock intended for one's opponent; (2) a ready signal, informing $S$ to depress a telegraph key; (3) a signal to release the key as fast as possible; and (4) a feedback signal that consisted of a light which indicated the amount of shock that the opponent had set for $\mathbf{S}$ and, if the opponent was faster, the shock as well.

In establishing the intensities of shock to be delivered to $S$, the intensity he judged "definitely unpleasant" was designated No. 5; No. 4 was set at $90 \%$ of that value, No. 3 at $80 \%$, No. 2 at $70 \%$, and No. 1 at $60 \%$.

\section{Results}

According to an analysis of variance of mean shock settings, neither the main effect of competition nor the interactions of competition with order or blocks were significant at the .05 level. The mean shock settings for the $\mathrm{MC}$ and $\mathrm{HC}$ conditions were, respectively, 1.93 and 1.99 . Thus, the competition manipulation had little influence on shock-setting behavior. The main effects of order and blocks and the Order by Block interaction also proved to be nonsignificant.

An analysis of variance of RT scores and subsequent Newman-Keuls tests revealed that, while the change in RT from Block 1 to Block 2 for the HC condition approached significance $(245.54$ to $235.68 \mathrm{msec}, \mathrm{p}<.06)$, there was no change in RT from Block 1 to Block 2 for the MC condition (247.68 to $246.64 \mathrm{msec}$ ). Furthermore, the difference between the mean RT for the $\mathrm{MC}$ and $\mathrm{HC}$ conditions in Block 2 approached significance (246.64 to $235.68 \mathrm{msec}$, $\mathrm{p}<.06)$. Thus, while the intense competition condition did not appear to affect Ss' aggressiveness, there is some evidence that it increased their motivation to win. This result appears to be consistent with the suggestion of Cofer \& Appley (1960) that placing "college students into a competitive situation with others increases the quantity or speed but not necessarily the quality of their work [p. 766]."'

It has been suggested by researchers such as Berkowitz (1969) that competition, like frustration, only increases a person's "readiness" to respond in an aggressive manner. Presumably, while a person may be primed to respond in an aggressive manner, an eliciting or provocative stimulus is required before the aggressive response can occur. In this study, all opponents continuously set minimal shock intensities; therefore, they did not provide eliciting cues. In Study 2, the opponent provides such cues by increasing the intensity of the shocks he directs at the $\mathrm{S}$.

\section{STUDY 2}

Subjects

The Ss were 30 male undergraduates enrolled in the introductory psychology classes at Kent State University. As in Study 1, they participated in order to earn experimental points in partial fulfillment of the course requirements. Apparatus and Procedure

The apparatus and task were the same as in Study 1. Following the determination of the "unpleasantness" threshold, Ss were assigned randomly to one of three competition conditions: (1) high competition (HC), in which Ss were informed that when they won on a particular trial, they would not receive a shock and would receive 5 cents; (2) moderate competition (MC), in which Ss were informed that when they won a particular trial, they would not receive a shock; (3) no competition (NC), in which Ss were told that $E$ had predetermined who would receive a shock on each trial.

Attack was treated as a within-S variable and increased across trials from low attack to high attack. The first block consisted of six trials, in which the feedback settings averaged 1.5. On three of the trials, the shock setting was " 1 " and in the other three trials, "2," The second block of trials consisted of feedback settings which averaged 2.5. In the third and fourth blocks, the average feedback settings were 3.5 and 4.5 , respectively. The sequences of wins and losses were programmed such that there were a total of 25 trials, four blocks of 6 trials each plus 1 additional trial, with each $S$ winning $50 \%$ of the trials within each block. Following the task, the $S$ s were given a questionnaire to assess their impressions of the task, their performance, and their opponent.

Results and Discussion

Analyses of variance of both Trial 1 settings and mean aggression settings in each block revealed no significant ef fects due to competition. However, there was a significant increase in aggression settings as a function of at tack $\quad(F=23.37, \quad d f=3 / 81$, $\mathrm{p}<.001)$. The average shock settings for Blocks 1-4, respectively, were 2.03 , $2.33,2.83$, and 3.39 .

While competition did not have a significant effect on aggression scores, analysis of the RT data did show a significant competition effect $(F=4.50, \quad d f=2 / 27, \quad p<.03)$, supporting the notion that RT may reflect Ss' motivation to win. The mean RTs for the $\mathrm{HC}, \mathrm{MC}, \mathrm{NC}$ groups were, respectively, $242.32,248.18$, and 274.28 msec. Newman-Keuls analysis showed that RTs for the NC group were significantly longer than those of the other groups, but that the remaining groups were not significantly different from each other. The slower RTs for the NC group suggest that they were less concerned with winning than were the other groups. This is supported by the fact that this group, on a postexperimental questionnaire, rated the importance of "having the fastest RT possible" significantly less than did the other groups. This group also indicated greater satisfaction with their RTs than did the $\mathrm{HC}$ and $\mathrm{MC}$ groups. While the RT means for the $\mathrm{HC}$ and $\mathrm{MC}$ groups were in the expected order, the lack of significant differences may have been due to a "ceiling effect." It is possible that differential motivation between these groups could not be exhibited because of the nature of the task (simple RT).

According to the results of Study 2, competition had little influence on the expression of physical aggression, even though Ss were provided with a justification to aggress. The effects of the attack variable, on the other hand, were clearly important in determining expression of aggression. This is consistent with both Buss (1966) and Taylor (1967), who have maintained that attack is a relatively potent antecedant of aggression.

In view of the results of Studies 1 and 2, it appears that the assumed relationship between competition and aggression must be reexamined. It is possible that writers such as Lorenz and Storr, who have postulated such a relationship, have confused the elements of attack and threat of attack which may occur in some competitive situations with the competition itself. That is, if one's opponent threatens or attacks, he may counteraggress. However, this is not unique to competitive situations, as may be seen in a series of studies done by Berkowitz (1962) in which noncompetitive tasks were employed.

Putting the results of the two studies together, it might be postulated that when attacked or threatened in a competitive situation, 
one will counterattack but that the competition per se does not appear to increase the likelihood that one will initiate the attack.

\section{REFERENCES}

BERKOWITZ, L. Aggression: A social psychological analysis. New York: McGraw-Hill, 1962.

BERKOWITZ, L. The frustration-aggression hypothesis revisited. In L. Berkowit2 (Ed) Roots of aggression. New York: Atherton Press, 1969. Pp. 1-28.

BERKOWITZ, L., \& LePAGE, A. Weapons as aggression-elicited stimuli. Journal of Personality \& Social Psychology, 1967, 1, 202-207.

BUSS, A. Instrumentality of aggression, feedback, and frustration as determinants of physical aggression. Journal of Personality \& Social Psychology, 1966, 3, 153-162.

CAPLOW, T. Principles of organization. New York: Harcourt, Brace, \& World, 1964.

COFER, C. N., \& APPLEY, M. H, Motivation: Theory and research. New York: Wiley, 1964.

DEUTSCH, M. The effects of cooperation and competition upon group processes.
Human Relations, 1949, 2, 199-231.

EPSTEIN, S., \& TAYLOR, S. Instigation to aggression as a function of degree of defeat and perceived aggressive intent of the opponent. Journal of Personality. $1967,5,265-289$.

LORENZ, K. On aggression. New York: Bantam Books, 1963

MILGRAM, S, Liberating effects of group pressure. Journal of Personality \& Social Psychology, 1965, 1, 127-134

RAPAPORT, A. Fights, games, and debates. Ann Arbor: University of Michigan Press, 1960

SHERIF, M., \& SHERIF, C. W. An outline of social psychology. New York: Harper \&e Row, 1956.

STORR, A. Human aggression. New York: Atheneum, 1968.

TAYLOR, $S$. Aggressive behavior and physiological arousal as a function of provocation and the tendency to inhibit aggression. Journal of Personality, 1967. $35,297-310$.

TAYLOR, S., \& PISANO, R. Physical aggression as a function of frustration and physical attack. Journal of Social Psychology, in press.

THIBAUT, J., \& KELLEY, H. The social psychology of groups. New York: Wiley, 1961.

\title{
Effects of topic relevancy and attitude similarity on two measures of affiliation*
}

\author{
JOHN J. LA GAIPA and RON E. WERNER \\ University of Windsor, Windsor, Ont., Canada
}

Ss were exposed to an anonymous stranger with similar or dissimilar attitudes on topics high or low in relevancy to friendship. Two judgments were made about the stranger: the degree of liking and the highest level of friendship that could be developed with him. Main effects for similarity and relevancy and a three-way interaction with type of judgment were found. Analysis of simple effects revealed that the attraction responses were a function of similarity and not relevancy. The expected level of friendship responses was influenced by the interaction effects of relevancy and similarity: relevancy had a highly significant effect under attitude similarity and not under attitude dissimilarity.

Byrne and his associates have conducted a series of studies on a deduction from interpersonal attraction theory (Newcomb, 1956), that the relationship between similarity and attraction varies with the importance and relevancy of the topic. The initial failures to demonstrate topic effects (Byrne \& Nelson, 1964, 1965) were later explained as consistent with the extended law of attraction (Byrne \& Rhamey, 1965), by which attraction is related to the weighted proportion of positive reinforcements associated with a person. When equal weights are assigned the positive and negative reinforcements, the weights cancel out

*The authors wish to thank A. Arthur Smith and Meyer Starr for their advice and useful comments. and no topic effect is evident. Topic effects on attraction were shown by differentially weighting topic importance or interest within each level of agreement-disagreement (Byrne, London, \& Griffith, 1968; Clore \& Baldridge, 1968). La Gaipa \& Werner (1971) were unable to replicate these 1968 findings in a study on topic relevancy. It was suggested that topic effects may have been obscured by any dissonance resulting from exposure to agreement and disagreement by the same stranger. The experimental design used in the present study was a return to that used by Byrne \& Nelson (1964, 1965 ) in that homogeneous, rather than heterogeneous, topics were associated with the stranger and equal weights were employed.

The basic assumption was that a difference exists in the relevancy to friendship formation of similar attitudes on friendship and similar attitudes on impersonal issues. Relevancy was defined in terms of the instrumental value of a topic to the receiver for a specific purpose or goal. It was hypothesized that agreement on the more relevant friendship topics would evoke a higher level of affiliation tendency than agreement on the less relevant impersonal topics.

\section{METHOD}

The same materials were used as in an earlier report (La Gaipa \& Werner, 1971). A shortened version of the friendship expectancy (FE) scale was used. The 20 items represented the subscales dealing with acceptance, admiration, openness, and ritualistic social exchange. The social attitudes (SA) scale contains 28 items on such impersonal topics as student power, authority, drugs, and sex. The items from the $\mathrm{FE}$ scale were originally rated by $\mathrm{Ss}$ as having higher relevancy for friendship than the items from the SA scale. The FE scale was designated as measuring topics of high relevancy and the SA scale as measuring topics of low relevancy.

A total of 40 undergraduate students in introductory courses in psychology at the University of Windsor particpated in the present study. Twenty Ss were administered the FE scale with instructions to rate each of the friendship statements on a 9-point scale according to how essential it was for maintaining a friendship with a social acquaintance. Twenty Ss were administered the SA scale with instructions to indicate the degree of agreement with each of the statements on a Likert-type scale.

About 1 week after the administration of the two scales, the Ss were returned bogus questionnaires prepared by the $\mathrm{E}$ to create two levels of agreement (.33 and .67). Topic relevancy was manipulated by the assignment of the more relevant $\mathrm{FE}$ or the less relevant SA scales to the Ss on which the stranger agreed (.67) or disagreed (.33). Four experimental conditions [were created. The stranger expressed agreement on the friendship items (similarity-high relevancy), disagreement on the friendship items (dissimilarity-high relevancy), agreement on the impersonal items (similarity-low relevancy), and disagreement on the impersonal items (dissimilarity-low relevancy). This design permitted each $S$ to respond only to one level of attitude similarity and one level of topic relevancy. Two affiliative types of judgments were made about the stranger: the degree of attraction and the potential level of friendship. The attraction measure was based on the last two items of the interpersonal judgment scale (IJS) 